\section{Temperature sensitive defect in human-hamster cell hybrid}

IN a recent report Talavera, Basilico and $\mathrm{Croce}^{1}$ reported incomplete complementation of a temperature-sensitive defect in $28 \mathrm{~S}$ ribosomal RNA (rRNA) maturation after hybridisation of a Syrian hamster line, BHK 21/13ts $422 \mathrm{E}$ and LW SV40 transformed human cells. The incomplete complementation was expressed as a significant decrease in the growth rate of the hybrid cells as well as a reduced level of $28 \mathrm{~S}$ rRNA production. In three of the hybrid populations tested, one contained exclusively BHK 28S rRNA and the other two showed a distribution of greater than $90 \%$ BHK $28 \mathrm{~S}$ rRNA and only a very small proportion of human $28 \mathrm{~S}$ rRNA. These results contrasted markedly with the situation with hybrids of the same BHK $t s 422 \mathrm{E}$ cells and two mouse lines in which good complementation was observed with the production of both mouse and hamster 28S rRNA at the non-permissive temperature $\left(39^{\circ} \mathrm{C}\right)^{2}$. The distribution of mouse and hamster 28S rRNA ranged from predominantly mouse to predominantly hamster with some hybrids showing an equal distribution of both

those utilising pathway $b$, such as human cells. Furthermore, assuming that the BHK $t s$ cells at $39^{\circ} \mathrm{C}$ cannot provide all of the products necessary for maturation by pathway $b$, one could also account for the low yields of human $28 \mathrm{~S}$ rRNA in the two hybrids analysed by Talavera et al. ${ }^{1}$, which are presumed to contain actively transcribing human rRNA genes. Since the BHK $t s 422 \mathrm{E}$ mutant at the permissive temperature $\left(33{ }^{\circ} \mathrm{C}\right)$ uses predominantly pathway $b$, characteristic of human HeLa cells $\mathrm{s}^{3.4}$, our interpretation leads to the testable prediction that at $33^{\circ} \mathrm{C} t s 422 \mathrm{E}$ should be able to provide the gene products necessary for human 28S rRNA production in the BHK $\times$ human cell hybrids F3 and F31.

The alternative explanations offered by us and by Talavera et al. are based on two different assumptions about the nature of the complementing function supplied by the $\mathrm{L}$ and HeLa cell partners in the hybrids with BHK cells. Given that the temperature-sensitive lesion in $t s 422 \mathrm{E}$ is pleiotropic in affecting both the cleavage at site 4 and the relative propensity for cleavage at sites 2 and 3 , it is conceivable that the lesion is one which affects the conformation of the preribosomal particles in the

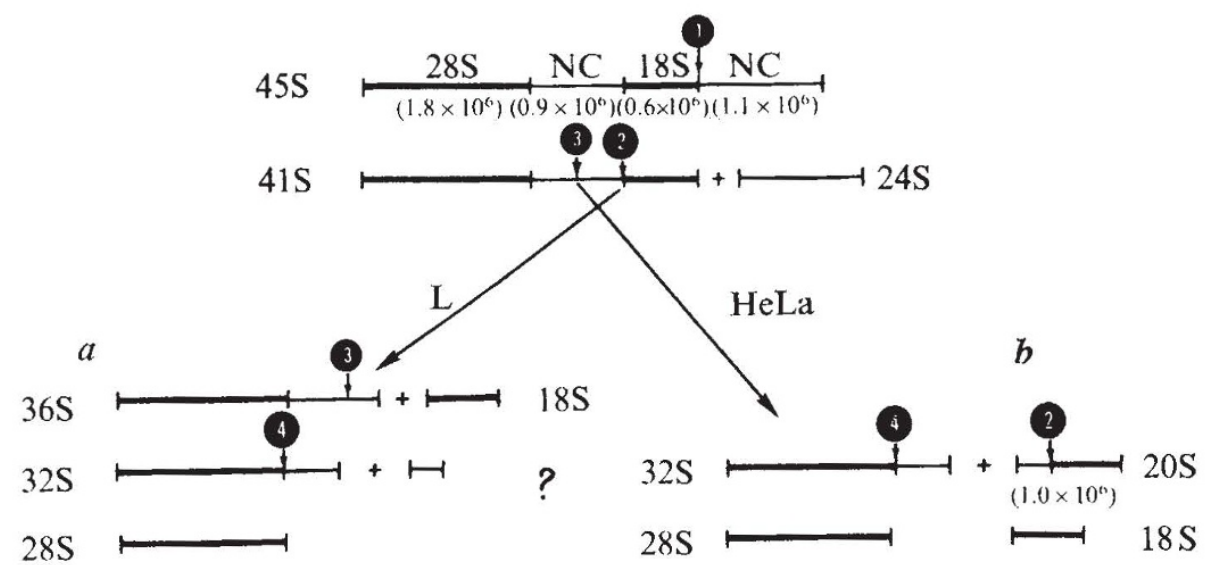

Fig. 1 The two pathways by which BHK t.s422E can process rRNA.

28S rRNA types. We would like to offer a possible explanation for the poor complementation observed in the BHK human hybrids based on our own published data ${ }^{3,4}$.

BHK $t s 422 \mathrm{E}$ can process rRNA by two alternative pathways as shown in Fig. 1: pathway $a$, which is characteristic of mouse $\mathrm{L}$ cells, and pathway $b$, which is characteristic of human HeLa cells. The BHK ts422E mutant at its non-permissive temperature $\left(39^{\circ} \mathrm{C}\right)$ uses pathway $a$, which in this case is defective at the $32 \mathrm{~S} \rightarrow 28 \mathrm{~S}$ step. In hybrids of $t s 422 \mathrm{E}$ one might therefore expect complementation by gene products from cells exhibiting pathway $a$, such as mouse cells, but not from regions of the relevant cleavage sites. The uncertainty is whether the complementing function restores the order of cleavages to pathway $b$, characteristic of the wild-typ BHK cells, or whether the complementing function simply enables the $t s 422 \mathrm{E}$ cells to utilise pathway $a$ more productively. The only essential feature of the complementation that was observed in the hybridisation experiments is that it restored the ability to make a proper cleavage at site 4 , which is required for viability at the non-permissive temperature. Whether the other consequences of the pleiotropic lesion are also complemented cannot be ascertained without a more detailed analysis of the process- ing pathway in the hybrid cells.

ILGA WINICOV

Robert P. Perry

The Institute for Cancer Research, Fox Chase Cancer Center,

Philadelphia, Pennsylvania, 19111

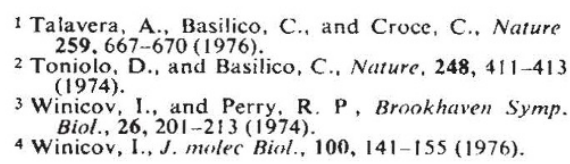

TAlAVERA ET AL. REPLY - The appearance of $36 \mathrm{~S}$ as well as $20 \mathrm{~S}$ nucleolar RNAs in wild-type BHK (refs 1 and 2) indicates that the two alternative pathways of ribosomal RNA (rRNA) processing described by Winicov and Perry ${ }^{1,3}$ are probably an effect of differential rates of cleavage at the sites 2 and 3 (Fig. 1 of ref. 1). Pathway $B$ could be absent in $t s 422 \mathrm{E}$ at $39^{\circ} \mathrm{C}$ because of a partial effect on site 3 of the lesion that blocks completely the cleavage at the neighbouring site 4 (ref. 2). This would favour cleavage at site 2 , resulting in a shift to pathway $A$. We therefore believe that pathway incompatibility alone cannot be taken as an explanation of the imperfect complementation found in hybrids between human cells and the BHK mutant $t s 422 \mathrm{E}$ (ref. 5).

Wt BHK cells as well as the mutant at $33{ }^{\circ} \mathrm{C}$ follow preferentially pathway $B$ (characteristic of human cells). Thus, a perfect complementation of the $t s$ defect in the human $\times t s 422 \mathrm{E}$ hybrid should produce both at $33^{\circ} \mathrm{C}$ and $39^{\circ} \mathrm{C}$ the use of pathway $B$, which is the preferred pathway of both parent cells.

On the other hand the low amount of human 28S rRNA found at $39^{\circ} \mathrm{C}$ in the hybrid populations $\mathrm{F} 3$ and $\mathrm{F} 31$ (ref. 5) can be explained according to Winicov and Perry ${ }^{4}$ only if one assumes that human rRNA processing functions are lost in the hybrids, as the parental human cells are not defective in rRNA processing. This seems unlikely; even if it cannot be completely excluded. As already discussed ${ }^{5}$, the selection and propagation of the hybrid lines should have strongly favoured cells which maintained the human chromosome(s) necessary to attain the highest possible level of 28 S RNA.

For these reasons we believe that the defective cross-specific rRNA processing in our hybrids is more likely to be caused by specific binding differences in the formation of preribosomal particles, rather than by incompatibility between different processing pathways.

\footnotetext{
1 Winocov, 1., J. molec. Biol., 100, 141-155 (1976).

2 Toniolo, D., and Basilico, C., Biochim. hiophys. Acta. 425, 409-418 (1976).

Winicov, 1., and Perry, R. P., Bronkhaven Symp. Biol., 26, 201-213 (1974).

4 Winicov, I., and Perry, R. P. Nature, 264682 (1976).

Talavera, A.. Basilico, C., and Croce, C. Nature, 259, 667-670 (1976).
} 